\title{
Impacts of water hyacinth treatment on water quality in a tidal estuarine environment
}

\author{
Vanessa D. Tobias $(\mathbb{D} \cdot$ J. Louise Conrad $(\mathbb{D} \cdot$ Brian Mahardja $(\mathbb{D} \cdot$ \\ Shruti Khanna $\mathbb{D}$
}

Received: 29 October 2018/Accepted: 18 July 2019/Published online: 31 July 2019

(C) The Author(s) 2019

\begin{abstract}
Water hyacinth (Eichhornia crassipes) is an invasive species that has modified ecosystem functioning in the Sacramento-San Joaquin Delta (Delta), California, USA. Studies in lakes and rivers have shown that water hyacinth alters water quality. In tidal systems, such as the Delta, water moves back and forth through the water hyacinth patch so water quality directly outside the patch in either direction is likely to be impacted. In this study, we asked whether the presence or treatment of water hyacinth with herbicides resulted in changes in water quality in this tidal system. We combined existing datasets that were originally collected for permit compliance and longterm regional monitoring into a dataset that we
\end{abstract}

V. D. Tobias $(\bowtie) \cdot S$. Khanna

California Department of Fish and Wildlife, Bay-Delta

Region, 2109 Arch-Airport Rd., Stockton, CA 95206,

USA

e-mail: vanessa_tobias@fws.gov

Present Address:

V. D. Tobias - B. Mahardja

United States Fish and Wildlife Service, 850 S. Guild Avenue, Lodi, CA 95240, USA

J. L. Conrad

California Department of Water Resources, 3500

Industrial Blvd., West Sacramento, CA 95691, USA

Present Address:

J. L. Conrad

Delta Stewardship Council, 980 9th Street, Sacramento,

CA 95814, USA analyzed with a before-after control-impact framework. This approach allowed us to describe effects of presence and treatment of water hyacinth, while accounting for seasonal patterns in water quality. We found that although effects of treatment were not detectable when compared with water immediately upstream, dissolved oxygen and turbidity became more similar to regional water quality averages after treatment. Temperature became less similar to the regional average after treatment, but the magnitude of the change was small. Taken together, these results suggest that tidal hydrology exports the effects of water hyacinth upstream, just as river flow is known to transport the effects downstream, creating a buffer of altered water chemistry around patches. It also suggests that although water hyacinth has an effect on dissolved oxygen and turbidity, these parameters recover to regional averages after treatment.

Keywords Estuaries - Temperature - Dissolved oxygen $\cdot$ Turbidity $\cdot$ Herbicide

\section{Introduction}

Invasive aquatic vegetation can change ecosystem functions such as physical structure, community composition, biogeochemical cycling, and hydrology (Bertness 1984; Vitousek 1990). For example, 
submerged aquatic vegetation alters sediment dynamics, making turbid water clearer (Hestir et al. 2015). Invasive aquatic weeds reduce water velocity substantially (Champion and Tanner 2000), impact water quality (Willoughby et al. 1993; Cordo and Center 2000; Masifwa et al. 2001), and provide habitat for non-native fish predators (Toft et al. 2003). Steps are often taken to manage the spread of these invasive species in order to reduce the impacts on environmental quality, boat navigation, and operation of water infrastructure.

Water hyacinth, Eichhornia crassipes (Mart.) Solms, is a particularly problematic invader. It is a floating perennial aquatic plant that most often colonizes freshwater aquatic habitats where water velocity is low. It is native to Brazil, but it has invaded 50 countries and five continents (Villamagna and Murphy 2010). Water hyacinth is one of the fastest growing macrophytes in the world (Wolverton and McDonald 1979) and it can profoundly change the ecosystems that it invades (Penfound and Earle 1948). Water hyacinth reproduces extremely quickly by producing daughter plants on stolons; 10 plants can produce a mat of 650,000 plants in one growing season (Penfound and Earle 1948). This rapid growth, coupled with its ability to spread over the surface of a water body, degrades water quality by altering physical, biological, and chemical processes.

Studies have shown that water hyacinth can alter water quality, but most of these studies have examined its impacts on temperature, dissolved oxygen, and turbidity in lakes or small flowing rivers. A tidal environment presents a type of hydrology that is different from either of these types of systems: rather than flow being unidirectional or largely static, flow is bidirectional with water parcels passing through a given area more than once per day. Because of these differences, it is unclear whether water hyacinth can affect water quality in tidal systems in a similar fashion as in lakes or streams. In systems with standing water, such as lakes and ponds, water hyacinth reduces variability in temperature (Rai and Munshi 1979; Bicudo et al. 2007), and this effect is most pronounced when dealing with very large, dense patches of water hyacinth in standing water (Penfound and Earle 1948; Lynch et al. 1947). Similarly, reductions of dissolved oxygen may vary spatially, depending on hydrology. In river systems, where water flows through large patches of water hyacinth, the water downstream becomes depleted of dissolved oxygen (Lynch et al. 1947; Perna and Burrows 2005). A study of dissolved oxygen in and around water hyacinth patches in the San Francisco Estuary (SFE; the San Francisco Bay and Sacramento-San Joaquin Delta) found that dissolved oxygen is reduced in areas with water hyacinth, relative to areas of open water (CDBW 2017). Hydrology also plays a role in turbidity. Increased flow has been associated with reduced turbidity in laboratory tests with floating aquatic plants (Zimmels et al. 2006) and in a reservoir, areas with water hyacinth had higher turbidity than sites without water hyacinth (Rommens et al. 2003). In tidal systems water moves back and forth through the patch so water quality directly outside the patch in either direction is likely to be directly influenced by the patch.

This study investigates how the presence of water hyacinth or the treatment of water hyacinth with herbicides changes water quality in a tidal freshwater system. This study specifically explores whether the presence or treatment of water hyacinth creates changes in water quality that are detectable when compared with baseline data that have been collected at different spatial scales. This study focused on temperature, dissolved oxygen, and turbidity because these water quality parameters have been shown to be important drivers in the growth and distribution of various fish species of high management interest in the SFE such as Chinook Salmon (Oncorhynchus tshawytscha) and the endangered Delta Smelt (Hypomesus transpacificus; e.g., Marine and Cech 2004; Mahardja et al. 2017; Polansky et al. 2018). We specifically asked (1) whether water quality parameters measured in water hyacinth patches differed from nearby open water and (2) whether the area that is influenced by water hyacinth patches differed from regional water quality patterns. We combined existing datasets that were originally collected for other purposes (specifically for permit compliance and for long-term regional monitoring) into a single dataset that we could analyze under a before-after control-impact (BACI) framework. This approach allowed us to look at the effect of presence as well as treatment, while accounting for seasonal patterns in water quality that occurred over the course of the study.

We conducted this study in the Sacramento-San Joaquin Delta, where water hyacinth is a major invasive species that has modified ecosystem functioning and vegetation community dynamics (Khanna 
et al. 2012). The Sacramento-San Joaquin Delta (hereafter, Delta) is a highly managed and socioeconomically important system that supplies drinking water to over 25 million people and irrigation water for more than 300 thousand hectares of farmland, supporting international agribusiness (CDWR 2013). In this system, management of water resources, including the treatment of aquatic invasive species, must consider the balance between societal demand for water and protection of endangered species. Although water hyacinth was introduced in 1904 (Finlayson 1983), in recent years the impacts on the Delta have been increasing. The extent of floating aquatic vegetation increased from 323 hectares in 2004 to over 2590 hectares in 2014 (a change from 1.3 to $10.6 \%$ of the area of the Delta) due to a combination of factors including recent droughts, milder winters, and delays in implementing control programs (Khanna et al. 2015). This expansion makes control efforts crucial to maintaining the socio-economic and ecological functions of the system.

The California State Parks Division of Boating and Waterways (CDBW) was first charged with controlling water hyacinth in 1982 (Garamendi and Nielsen 1982). The goal of the control program is to control invasive plant cover that harms the State's economy, navigation, or public health (CDBW 2016). The control plan leverages a suite of control tools, mainly consisting of chemical treatment with some mechanical removal (CDBW 2012). The program prioritizes treatment of areas that serve as nurseries for water hyacinth as well as areas where it negatively impacts safety, water infrastructure, or boat navigation. In this study, we used water quality data collected by CDBW as part of routine monitoring for herbicide application sites.

The results of this study show that water quality around water hyacinth patches is similar to water quality within the patch in a tidal environment, probably because of daily water movement in and out of the patch. However, when using a regional baseline for analysis, it is apparent that water quality in the vicinity of water hyacinth patches is different after herbicide treatment. In addition to the direct implications for water management the Sacramento-San Joaquin Delta, these results are also generalizable to estuaries worldwide because of the cosmopolitan distribution of water hyacinth.

\section{Methods}

\section{Study system}

The San Francisco Estuary (SFE) is located in Northern California and comprises the San Francisco Bay (Bay) and the Sacramento-San Joaquin Delta. Two rivers, the Sacramento and San Joaquin, are the primary contributors of water to the SFE. Downstream of the confluence of these two rivers, fresh water flows west and becomes more saline as it moves through the Bay toward the Pacific Ocean. Upstream of the confluence is the area known as the Delta, and this is the area where our study took place. Much of this area was once wetland and riparian areas, but now consists largely of channels separating islands that have been converted to agriculture or urban areas. The water that flows through the SFE is highly managed to maintain low salinity in the Delta, based on standards set by the State Water Resources Control Board, and to provide water deliveries to the State Water Project and Central Valley Project, the two major water infrastructure systems that transport water from the northern to the southern portion of the state. As a result, the area upstream of the confluence of these two rivers forms a freshwater region in which tides influence water movement, but not salinity. Tides in this region follow a semi-diurnal pattern, with a maximum vertical range of approximately $1.5 \mathrm{~m}$. The Delta spans roughly 24,000 hectares (Fig. 1), and the watershed that drains into it comprises $40 \%$ of the area of California (Jassby and Cloern 2000). The region has a Mediterranean climate, with cool, wet winters and warm, dry summers.

Field collection of water quality

To address our questions regarding changes in water quality as a result of water hyacinth treatment, we leveraged two existing water quality datasets: (1) discrete data collected at treatment sites by CDBW; and (2) high-frequency (every $15 \mathrm{~min}$ ) water quality data collected by the California Department of Water Resources (CDWR) at a series of locations near selected treatment sites.

As part of the National Pollutant Discharge Elimination System (NPDES) permit for discharge of herbicide for aquatic weed control (No. CAG990005, Water Quality Order 2013-0002-DWQ), CDBW 


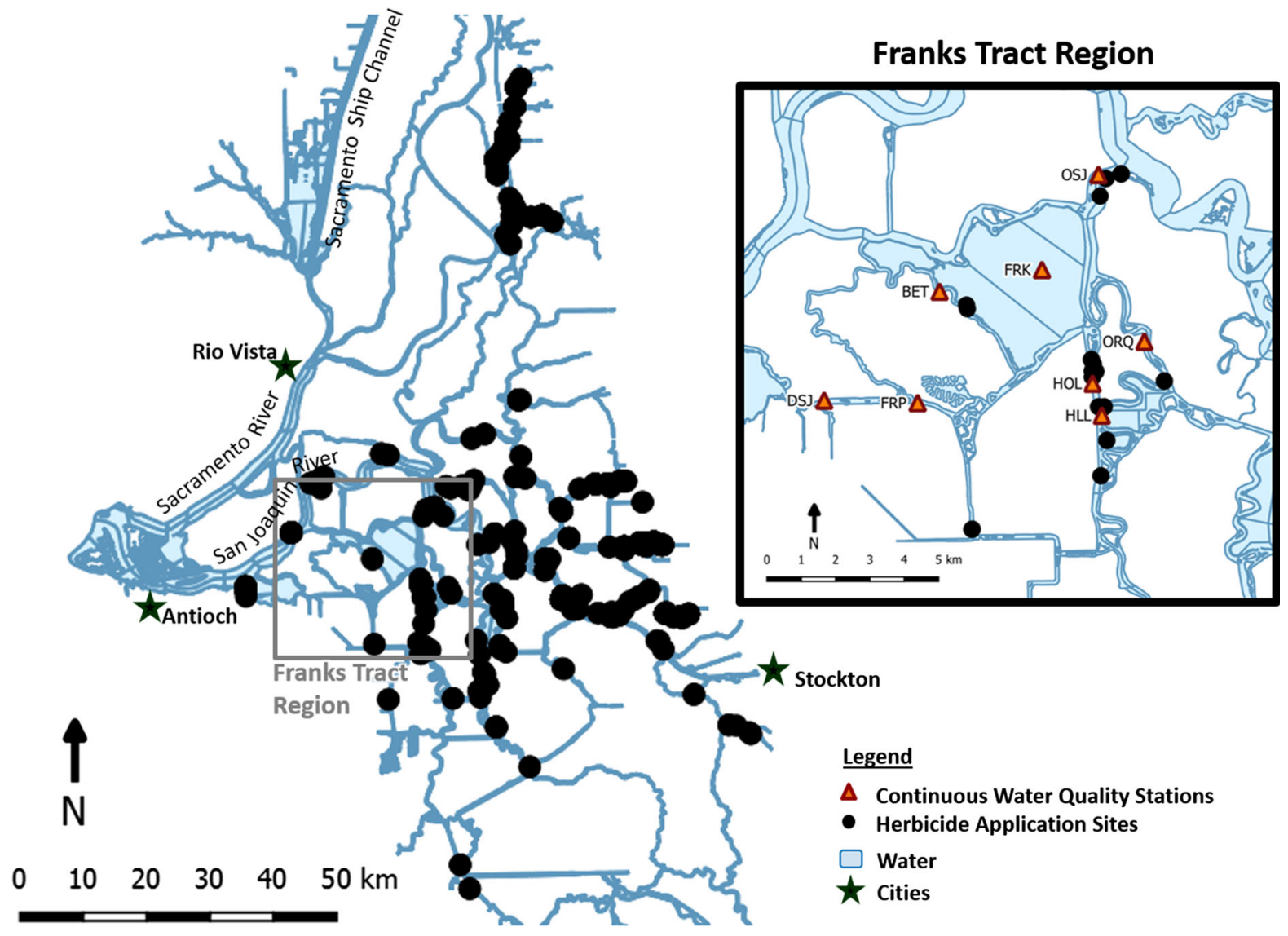

Fig. 1 Locations of treated patches of water hyacinth throughout the Delta with an inset map showing locations of continuous water quality stations in the Franks Tract region that were used in the calculation of regional baseline values. Labels for water

monitors water quality in and around the water hyacinth patches that are treated. Water quality is measured at two locations in and around the patch of vegetation (Fig. 2). Sample sites are located inside of the treated patch of vegetation and in an adjacent nonimpacted area with similar hydrological conditions as the treated patch, $30.5 \mathrm{~m}$ upstream of the treatment area (CDBW 2013). CDBW also takes a sample $7.6 \mathrm{~m}$ downstream of the patch in some cases, but we did not use the downstream measurements in this analysis because it was collected less frequently than other locations. Upstream and downstream directions are relative to net flow and may not indicate the direction of water flow at all times because of the tidal hydrology at these locations. The area CDBW treated for water hyacinth each year varied from 170 to 1800 hectares. The amount of area treated depended on quality stations correspond to station names used on the California Data Exchange Center (CDEC 2018; https://cdec. water.ca.gov/)

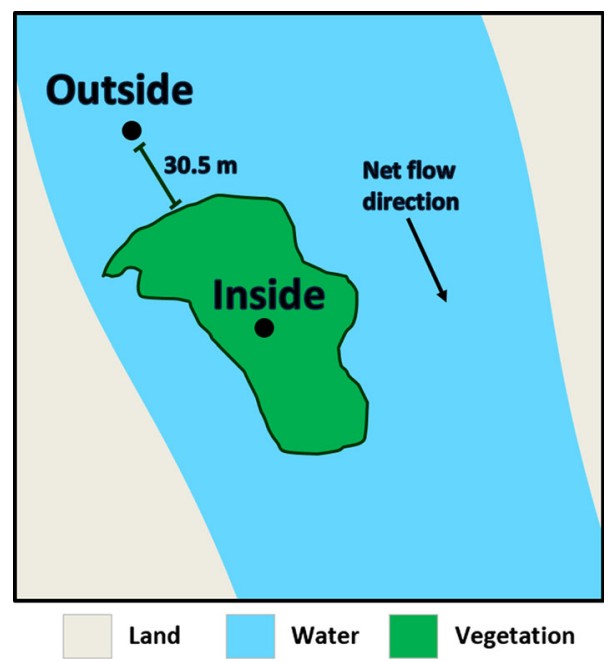

Fig. 2 Diagram of sampling locations relative to a treated patch of vegetation 
several factors, including the magnitude of the infestation, regulatory restrictions, weather, and staffing levels (CDBW 2016). Water hyacinth can be treated between March 1 and November 30, but the timing of applications depends on the region (CDBW 2013). The herbicides used include Glyphosate, 2,4-D, and, in rare cases, Imazamox, depending on the year and location of the water hyacinth plants. The adjuvants Agridex and Competitor have also been included in the control plan. Sites that are infested with water hyacinth may be treated up to six times during a season.

Water quality parameters including temperature, dissolved oxygen, and turbidity were measured immediately before herbicides were applied and approximately one week after application. Water quality measurements were taken at a depth of $1 \mathrm{~m}$ using a Hydrolab ${ }^{\circledR}$ Model MS5 mini datasonde, in compliance with monitoring procedures for the NPDES permit. The purpose of water quality monitoring sampling is to ensure that changes in water quality do not exceed limits described in the Central Valley Basin Plan and those required by the NPDES permit. No data were available on the presence or absence of water hyacinth after herbicide treatment; however, CDBW reports generally that symptoms of herbicide effectiveness, including death of water hyacinth plants were observed from all treatments (CDBW 2016). Additional details about methods, rationale, and reporting requirements are available in the $\mathrm{CDBW}$ reports and permit documentation on the CDBW website (www. dbw.ca.gov).

Continuous water quality monitoring stations in the Franks Tract region with sensors for temperature, turbidity, and dissolved oxygen were identified using metadata available on the California Data Exchange Center (CDEC 2018; cdec.water.ca.gov). The Franks Tract region is approximately $10 \mathrm{~km}$ wide and it contained eight stations that collect water quality information at 15-min intervals (Fig. 1). None of these stations was within $30 \mathrm{~m}$ of an area where water hyacinth was treated, and thus did not have spatial overlap with CDBW water quality sampling. Water quality data are available for direct download on CDEC, but these data have not undergone QA/QC so we requested datasets directly from CDWR, the agency that maintains the deployed sensors. QA/QC procedures consisted of filtering data for values outside the range of sensors, inspecting individual water quality parameters for abrupt changes over time, and flagging missing values. Sondes were calibrated prior to deployment and after deployment the total deviation between the sonde and the calibration standard were measured and recorded for data correction purposes.

We used the data from continuous water quality recorders to calculate regional water quality averages. The purpose of this calculation was to define how water quality conditions changed in the region overall during the treatment period. This is particularly important for water quality parameters that are strongly seasonal, tidal, or episodic, such as temperature and turbidity. Without a baseline for comparison, we might erroneously attribute changes in water quality to the treatment that were simply related to seasonal water quality patterns. To calculate the regional water quality averages, the 15 -min intervals for each water quality parameter were summarized by date and hour for each station. For example, the hourly average for 08:00 was calculated as the arithmetic mean of the measurements taken at 08:00, 08:15, 08:30, and 08:45 on a particular date. After these hourly means were calculated for individual stations (Fig. 1), they were averaged across stations to produce an hourly regional average for that date. Means included measurements only for the morning and through early afternoon (08:00 to 15:00) because this was the time of day when the CDBW water samples were taken. The final dataset of regional averages contained a mean value for each water quality parameter for each hour and day combination as well as a standard deviation for that value and the number of stations that comprise the mean. The variation of values across individual stations during an hour was small (coefficients of variation: temperature 0.02, dissolved oxygen 0.06 , turbidity 0.37 ). This approach of using several stations, each with multiple measurements, provided a very general picture of conditions, such that any unique characteristics of individual stations at particular times of the day would not have undue influence on analyses. This was important because we used these averaged values later to calculate the difference in conditions at water hyacinth treatment sites compared to regional averages. For this portion of the analysis, the regional average must be a general condition rather than indicative of single locations. 
Data analysis

We examined the effect of treatment of water hyacinth on water quality at two spatial scales. First, we compared the effects of treatment on a local, or treatment area, scale. This approach looked at differences in water quality before and after treatment at locations inside and upstream of patches of water hyacinth. The local scale analysis used only data collected by CDBW for the NPDES permit. No differences were found between water quality inside and outside the patches, likely because either the treatment did not affect water quality or the spatial scale of the effect was wider than the distance between the samples. To tease out the cause, we also looked at the effects of treatment relative to region-wide measurements of water quality; that is, using a regional baseline. To do this, we pooled observations in and around water hyacinth patches and compared them to the aforementioned regional water quality averages. All statistical comparisons were made using R (R Core Team 2016). We used 0.05 as the cutoff value for significance in our tests, but we report $\mathrm{p}$ values so readers can make their own determinations of significance.

The design of the NPDES monitoring created pairs of impacted (sprayed) and upstream control (unvegetated, not sprayed) sampling locations. We leveraged this sampling design to assess the effect of water hyacinth treatment on water quality at a local scale. Specifically, we used a Generalized Linear Mixed Model (GLMM), and a BACI design (Green 1979). The BACI design was developed to detect environmental disturbance by comparing measurements inside and outside the impacted area, both before and after a disturbance event occurs. In our study, instead of a disturbance, the event was applying herbicide treatment to water hyacinth. The GLMM that we used is equivalent to a two-way Analysis of Variance (ANOVA) that includes the main effects, location (inside, outside; Fig. 2) and time (before, after), and their interaction. In a BACI model, the test for a significant effect of herbicide treatment is the interaction between location and time. The ANOVA also included a random effect for site nested within year to pair samples on the same site within a treatment season. We fit a separate model for each water quality parameter (temperature, dissolved oxygen, and turbidity; function lmer, package lme4; Bates et al. 2015). A likelihood ratio test determined whether the models were significantly better than a null model consisting of only an intercept and the random component (function anova in package stats; R Core Team 2016). For models that fit better than the null, we investigated whether there were significant differences in the location (function lmer in package lmerTest version; Kuznetsova et al. 2016; anova; R Core Team 2016).

To address the question of regional changes in water quality as a result of treatment, we used the concept of an anomaly by comparing the CDBW discrete data and baseline data from the regional water quality averages calculated from high-frequency data. Water quality anomalies are calculated by subtracting the regional average from the measurement taken at the treatment site (anomaly $=\mathrm{CDBW}$ measurementregional average) taken in the same hour. Anomaly values can be interpreted as follows: an anomaly value of 0 indicates that the water quality value in the patch sample was equal to the regional average; an anomaly value greater than 0 indicates that the water quality value in the patch sample was higher than the regional average; and an anomaly value less than 0 indicates that a water quality value in the patch sample was lower than the regional average. This method allows the continuous measurements to form the baseline to interpret changes over time. It allows us to distinguish whether changes are attributable to the treatment or simply to changes that are occurring in the region.

As with any analysis that integrates data from multiple sources, temporal overlap can be a factor that limits the amount of data available for the analysis. Although data have been collected for the NPDES permit since 2004, continuous water quality sensors were not installed until later (Fig. 3). Issues with

\section{Data Availability in Franks Tract Region}

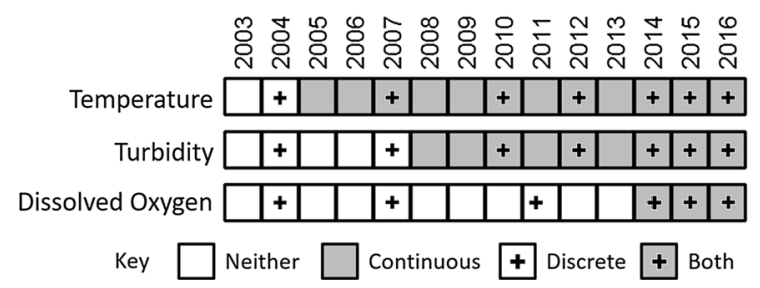

Fig. 3 Availability of temperature, turbidity, and dissolved oxygen datasets for the Franks Tract region by year. Anomalies where calculated where both continuous and discrete data were available 
temporal overlap did not impact comparisons for temperature and turbidity, but continuous sensors for dissolved oxygen were not in place until 2014, so comparisons for this water quality variable were only for 2014-2016.

To test whether the pre-treatment water quality anomalies were different than the post-treatment water quality anomalies we used a GLMM, which was similar to the GLMM used for the local scale analysis. For this test, the GLMM we used was equivalent to a one-way ANOVA including only a main effect for time (before, after) with a random effect for site. As in the tests for differences in and around patches, the ANOVA also included a random effect for site nested within year to properly pair samples on the same site within a treatment season. This method tests for differences among groups while accounting for taking multiple measurements on the same site. We fit separate models for each water quality parameter. As with the BACI models, models for differences in anomalies were fit using function lmer in package lme4 (Bates et al. 2015). Tests of significance were performed using a likelihood ratio test against a null (intercept-only) version of the model (anova; R Core Team 2016; test statistic $=$ D).

To make this information more widely applicable to any potential treatment site, it is useful to know whether we should expect the value of each water quality parameter to go up or down following treatment with herbicides and whether these values differ from the regional averages. To determine this information, we calculated marginal means and standard deviations using the models from the second question (function ref.grid, package 1smeans; Lenth 2016). These marginal means represent the expected value of water quality anomalies at a site before or after treatment, regardless of the site in question.

\section{Results}

When compared with the local baseline data (i.e., measurements taken $30 \mathrm{~m}$ upstream of the patch), there was no evidence that differences in any of the three water quality parameters were driven by the treatment of water hyacinth (i.e., the location $\times$ time component was not significant; Table 1). The fit of the model for effects of time and location on temperature was similar to that of the intercept-only model, but the models for dissolved oxygen and turbidity were better than the intercept-only model (Table 1). There was no evidence that treatment with herbicides affects either dissolved oxygen or turbidity (location $\times$ time) when using local baseline data, but dissolved oxygen concentration was higher on average at both locations after treatment than before treatment. Additionally, turbidity was lower outside the patch than inside after treatment (Fig. 4).

When using a regional mean as the baseline for comparing water quality before and after treatment, changes in water quality after treating water hyacinth are more apparent at our treatment sites than when we used a local baseline for comparison. Differences in water quality values at the treatment site relative to regional baseline were significantly different before and after treatment for temperature and dissolved oxygen, but not for turbidity (i.e., comparing anomalies at a site before and after treatment; temperature: $\mathrm{D}=8.69, p<0.01 ;$ dissolved oxygen: $\mathrm{D}=5.058$, $p=0.02$; turbidity: $\mathrm{D}=2.98, p=0.08$ ).

Using marginal estimates of means to determine the expected values of water quality parameters, regardless of site, the difference between the treatment area and the regional baseline (i.e., the anomaly value) increased after treatment for both water temperature and dissolved oxygen (Fig. 5). Temperature measurements were similar to the regional average before treatment, but were higher than the regional average after treatment (Fig. 5a). Dissolved oxygen was lower than the regional average before treatment, but became similar to the regional average after treatment (Fig. 5b). Turbidity was higher than the regional average before treatment, but became similar to the regional average after treatment (Fig. 5c). It should be noted that the confidence intervals for the marginal estimates are wider than the confidence intervals for the site-specific before-after results given above because they do not account for the repeated measures on each site; hence visually comparing means based on the confidence intervals in Fig. 5 does not produce the same results.

\section{Discussion}

The results of this study show that in a tidal system, the effects of water hyacinth are not confined to the area of the patch itself, but rather are evident in a wider area of 
Table 1 Model fit information and $p$ values for a BACI test of water quality parameters

\begin{tabular}{lccc}
\hline & Temperature & Dissolved oxygen & Turbidity \\
\hline Model significance & & & \\
Likelihood ratio & 0.80 & 24.8 & 12.2 \\
$p$ value & 0.85 & $<0.01$ & 0.01 \\
Marginal p values for fixed effects & & & $<0.01$ \\
Intercept & 0.01 & 0.14 & $<0.01$ \\
Location & 0.94 & $<0.01$ & 0.13 \\
Time & 0.50 & 0.19 & 0.05 \\
Location $\times$ time & 0.92 &
\end{tabular}

The BACI test was a two-way ANOVA where the fixed groups were location and time, with a random effect for sites to account for repeated measurements at the same sites. Location indicates inside or outside the vegetation patch. Time indicates before or after treatment of the patch with herbicides. Model significance shows the results of a likelihood ratio test of fixed effects portion of the model against a null (intercept-only) model with an identical random component. $p$ values for individual fixed effects are marginal $p$ values (fitted last; type 3). Models were fit using all available data (all regions)

(a)

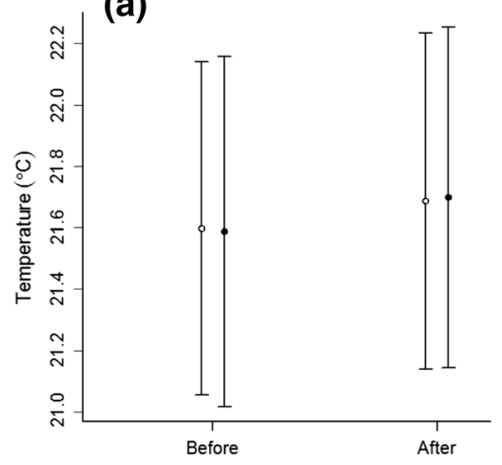

(b)

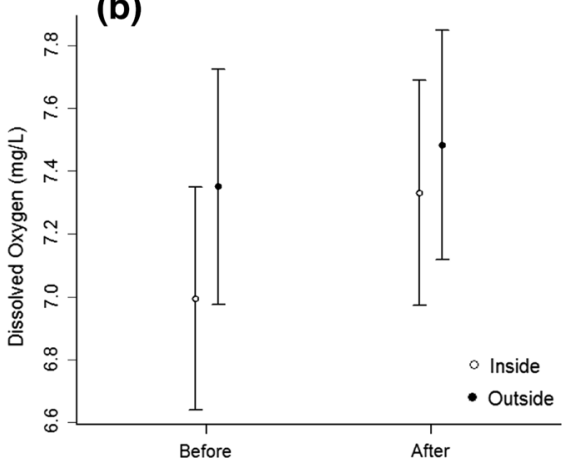

(c)

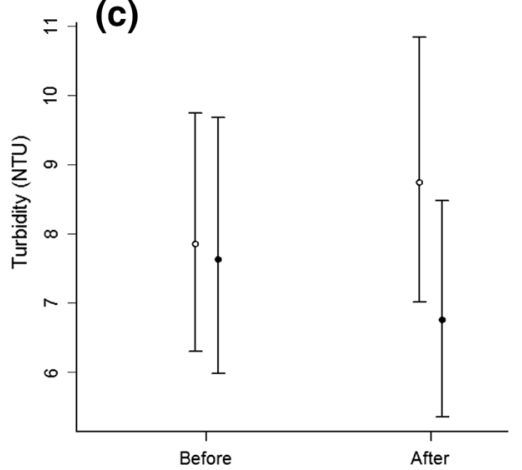

Fig. 4 Marginal estimates of means (with 95\% CIS) of a temperature, b dissolved oxygen, and $\mathbf{c}$ turbidity before and after treatment with herbicides at locations inside and outside the patch. (See Fig. 1 for a diagram of sampling locations.)

(a)

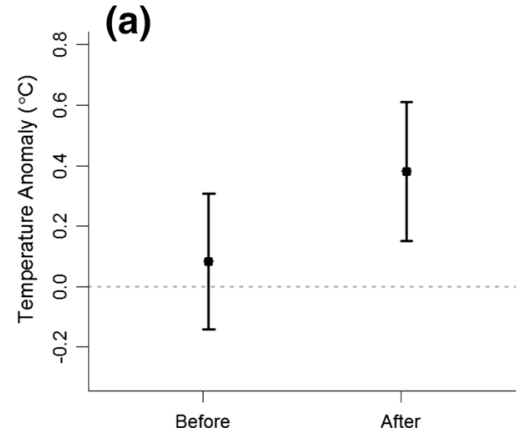

(b)

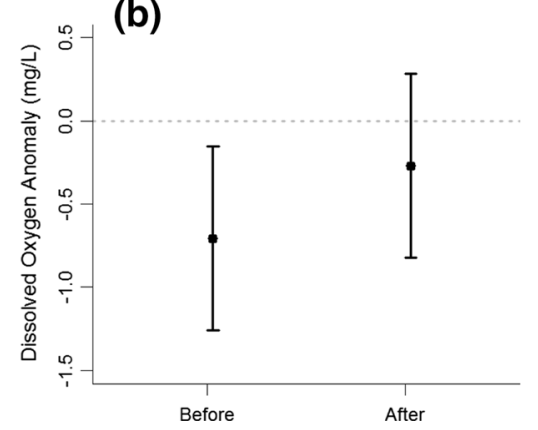

(c)

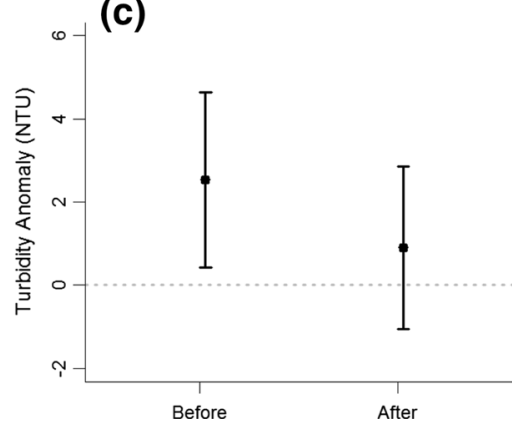

Fig. 5 Marginal estimates of anomalies (means and 95\% confidence intervals, calculated by LS Means; R function ref.grid in package lsmeans) for a temperature, $\mathbf{b}$ dissolved

the channel around a patch, including the area upstream of the patch. Effects of the presence and oxygen, and $\mathbf{c}$ turbidity. Marginal estimates are the average response expected, regardless of site identity. The dashed line represents the regional average

treatment of hyacinth on water quality may not be discernable when using a baseline local to the 
treatment area because the water chemistry inside a patch of water hyacinth and adjacent to it is similar, even when the baseline for comparison is upstream of the patch. This is likely because of the tidal hydrology in the Delta (Stacey et al. 2010). Water moves upstream and downstream twice per day, exporting the effects of water hyacinth towards outside the patch and diluting the impacts of water quality within the patch with outside water. When compared with a regional baseline, rather than a local one, the effects of presence and treatment of water hyacinth are clearer. Taken together, these results suggest that tidal hydrology creates a buffer of altered water chemistry around patches. Future studies in tidal systems should measure how water quality changes with distance from a patch of water hyacinth, both upstream and downstream, in order to determine the extent of its impacts.

Using a local baseline, this study found no significant difference between temperature of water inside the water hyacinth patch and outside and no effect of treatment on water temperature. Previous studies have shown that water hyacinth primarily affects water temperature by reducing variability in the vicinity of the patch (Rai and Munshi 1979; Bicudo et al. 2007), rather than increasing or decreasing temperatures in a single direction. The presence of water hyacinth can affect water temperature through two physical mechanisms: (1) it slows water movement (Penfound and Earle 1948), which may increase temperature by increasing residence time, and conversely, (2) it intercepts solar radiation by shading the water column, which may decrease temperatures. When compared with the regional baseline, temperatures were slightly higher than the regional baseline after treatment. This shift, although statistically significant, was small (approximately $0.3{ }^{\circ} \mathrm{C}$ ). Temperatures observed in this study were near the upper tolerance range for the endangered and SFE endemic fish species Delta Smelt $\left(25^{\circ} \mathrm{C}\right.$; Swanson et al. 2000; Nobriga et al. 2008), so even a small upward shift in temperature may limit their distribution. Temperatures above $25{ }^{\circ} \mathrm{C}$ limit the distribution of delta smelt more than temperatures at the low end of their tolerance (Nobriga et al. 2008). Chinook Salmon also have similar thermal tolerances, with temperatures above $24{ }^{\circ} \mathrm{C}$ being lethal, but with a thermal optimum below $18{ }^{\circ} \mathrm{C}$ (Marine and $\mathrm{Cech}$ 2004).

Effects of treatment on dissolved oxygen were not detectable when compared with water immediately upstream, but dissolved oxygen and turbidity became more similar to regional water quality averages after treatment. The rapid growth and production of detritus is likely the mechanism through which water hyacinth impacts both dissolved oxygen and turbidity. Because water hyacinth grows so rapidly, the mats constantly produce detritus, which decomposes and increases oxygen demand in the water column. When water is stationary, detritus that falls from water hyacinth remains under the patch. This contributes to lower dissolved oxygen and higher turbidity that has been documented under water hyacinth patches in lakes and ponds (Rai and Munshi 1979; Zimmels et al. 2006). In areas where water hyacinth mats are dense enough to form peat at the surface, the decreases in dissolved oxygen are more pronounced (Penfound and Earle 1948; Waltham and Fixler 2017). Although water hyacinth in the SFE does not commonly form peat, there is evidence to suggest that in other systems when water flows through large aggregations of water hyacinth, dissolved oxygen downstream becomes depleted (Lynch et al. 1947). In river systems where multiple mats of water hyacinth occupy a channel, dissolved oxygen content of the water gradually decreases in the downstream direction (Perna and Burrows 2005). In the SFE, water hyacinth has been shown to reduce dissolved oxygen levels in places with tidal exchange, particularly in association with shredding of the plant and decomposition (Greenfield et al. 2007).

Dissolved oxygen increased in the area around the patch as well as within the patch after treatment, relative to the regional baseline. The rate of recovery for dissolved oxygen depends on the velocity of the water in the channel, with dissolved oxygen rebounding within 2 weeks for flowing water and over 2 months for static water in lakes (Lynch et al. 1947). After accounting for regional patterns in dissolved oxygen, post-treatment values were higher than pre-treatment values. Since the dissolved oxygen numbers increased towards the regional average, this result indicates that the water hyacinth patches were negatively impacting dissolved oxygen values and that removing the water hyacinth caused dissolved oxygen to rebound to levels that are closer to the regional average. It should be noted, however, that dissolved oxygen levels remained above levels that impact fish species of concern in this system. For example, for Chinook Salmon and Steelhead (Oncorhynchus 
mykiss) dissolved oxygen less than $6.5 \mathrm{mg} / \mathrm{L}$ impacts swimming abilities and concentrations less than $2.5 \mathrm{mg} / \mathrm{L}$ are lethal (Newcomb and Pierce 2010). Although the dissolved oxygen levels observed in this study are unlikely to lead to fish avoidance or death, spraying dense hyacinth patches can lead to hypoxia (Waltham and Fixler 2017). This situation would be most likely to occur in dead-end sloughs where the water surface is completely covered by water hyacinth.

For the locations we studied, the effect of water hyacinth on turbidity was similar to that found in ponds. In places with moving water, dense floating mats of water hyacinth can further reduce flow once it establishes itself in low-flow areas (Penfound and Earle 1948), engineering a more pond-like environment that favors additional spread of water hyacinth. The higher turbidity values inside the patch relative to the local baseline supports the interpretation that shedding of detritus is the driver of turbidity differences. Similar results were found in a reservoir in Zimbabwe, where sites with water hyacinth had higher suspended solids than sites without water hyacinth (Zimmels et al. 2006). The net effect of water hyacinth on turbidity may depend on the prevailing turbidity of the system as well as the hydrology. In laboratory experiments with high turbidity waters (130-250 NTU), water hyacinth served as a net turbidity sink because water hyacinth roots contributed to settling of turbidity from external sources by slowing water flow (Zimmels et al. 2006). This effect of causing sediment to settle out of the water column may overwhelm the contribution of detritus to turbidity where the prevailing turbidity in the system is high and where water hyacinth reduces flow substantially. Turbidity levels observed in our study were low, but during freshwater flushing events turbidity levels in the Delta can be similar to those in Zimmels et al. (2006) and Ruhl and Schoellhamer (2004); however, high flows would also likely dislodge and break up water hyacinth mats. If turbidity from external sources was much greater than the turbidity generated by the detritus produced by water hyacinth plants, water hyacinth could become a net sink for suspended sediment in high turbidity areas of the Delta, but additional research is needed in this area to understand patterns between turbidity and water hyacinth presence.

This study could have benefitted from data on whether water hyacinth was present after treatment; however, data on the efficacy of herbicide treatments are not available. We assumed that vegetation treated with herbicides showed some reduction in cover and/ or biomass and that there is some tissue death. Anecdotal evidence from CDBW staff supports this assumption. Increases in dissolved oxygen in the posttreatment period, compared to the regional baseline, are consistent with effective removal of water hyacinth plants. If the herbicide has not completely eliminated a mat, the continuing presence of water hyacinth might weaken the results of this study. Taking measurements after a longer time gap since herbicide application might have also shown stronger effects on water quality because the herbicide would have had a longer time to eliminate the mat. The current study design could be improved by increasing the frequency and duration of data collection, possibly by installing water quality sondes to collect continuous water quality data near or within a patch. Future monitoring effort should also consider collecting data on the efficacy of the herbicide treatment. In particular, it would be useful to record the presence of yellowing to indicate slowed growth and whether the mat persisted at the site when water quality data were collected.

\section{Conclusions}

Although water hyacinth generally occurs in places with little to no flow such as lakes and canals, it also thrives in the tidally influenced SFE in shallow water habitats and other low-velocity areas. These hydrologic conditions create a set of habitat conditions that is different than other systems where water hyacinth effects on water quality have been extensively studied. The tidal hydrology moves water in and out of water hyacinth patches, such that effects of water hyacinth on water quality can readily be exported to surrounding areas. In our study, dissolved oxygen and turbidity became more similar to regional averages after treatment, which suggests removing water hyacinth may return habitat and water quality values to their pre-infestation state. A comprehensive water quality data collection, additional information on the success of herbicide treatment, and studies that focus on changes to fish assemblages are crucial to informing management about the effect of water hyacinth and its 
control efforts on the SFE ecosystem, including species of concern.

Acknowledgements This project is a product of the Interagency Ecological Program (IEP) Synthesis Team. Funding for the salaries of V. Tobias and S. Khanna was provided by a contract with the United States Bureau of Reclamation (Agreement R15AC00094 IEP Bay-Delta Fish and Aquatic Resources Monitoring, Objective 5.2: Management Analysis and Synthesis Team IEP-046). Angela Llablan (California Department of Fish and Wildlife, formerly CDBW) prepared and shared data. Edward Hard (CDBW) coordinated collaboration between $\mathrm{CDBW}$ and other agencies involved in this study. Many additional staff members at CDBW contributed to water hyacinth treatment and data collection. Mike Dempsey (CA Department of Water Resources) provided continuous water quality data and documentation. Continuous water quality data were collected by CA Department of Water Resources Division of Integrated Regional Water Management North Central Region Water Quality Evaluation Section, and Division of Environmental Services - Environmental Monitoring Program. Many members of the IEP Aquatic Vegetation Project Work Team and Science Management Team provided comments on early drafts and presentations. Data were collected under a National Pollutant Discharge System (NPDES) permit for discharge of herbicide for aquatic weed control (No. CAG990005, Water Quality Order 2013-0002-DWQ). The views and opinions expressed in this article are those of the authors and do not necessarily reflect the official policy or position of the U.S. Fish and Wildlife Service, the California Department of Water Resources, or the California Department of Fish and Wildlife.

Open Access This article is distributed under the terms of the Creative Commons Attribution 4.0 International License (http:// creativecommons.org/licenses/by/4.0/), which permits unrestricted use, distribution, and reproduction in any medium, provided you give appropriate credit to the original author(s) and the source, provide a link to the Creative Commons license, and indicate if changes were made.

\section{References}

Bates D, Maechler M, Bolker B, Walker S (2015) Fitting linear mixed-effects models using lme4. J Stat Softw 67(1):1-48. https://doi.org/10.18637/jss.v067.i01

Bertness MD (1984) Habitat and community modification by an introduced herbivorous snail. Ecology 65:370-381

Bicudo DD, Fonseca BM, Bini LM, Crossetti LO, Bicudo CE, Araújo-Jesus T (2007) Undesirable side-effects of water hyacinth control in a shallow tropical reservoir. Freshw Biol 52:1120-1133

California Data Exchange Center (CDEC) (2018) Available online: http://cdec.water.ca.gov/. Accessed 23 July 2018

CDBW (2012) Water hyacinth control program biological assessment. Oct 25 2012. Sacramento CA. http://www.
dbw.ca.gov/pages/28702/files/WHCP-Biological_ Assessment-121025.pdf

CDBW (2013) Water hyacinth control program and spongeplant control program aquatic pesticide application plan. Sacramento CA. http://www.dbw.ca.gov/pages/28702/files/ WHCP $\% 20$ SCP $\% 20$ Aquatic $\% 20$ Pesticide $\%$

20Application\%20Plan\%202013.pdf

CDBW (2016) Floating aquatic vegetation control program water hyacinth and spongeplant control projects 2015 annual monitoring report. Jan 11 2016. Sacramento CA. 2015. http://www.dbw.ca.gov/pages/28702/files/2015Annual-Report-FAV.pdf

CDBW (2017) Floating aquatic vegetation control program water hyacinth spongeplant and water primrose 2016 annual monitoring report. Jan 31 2017. Sacramento CA. 2016. http://www.dbw.ca.gov/pages/28702/files/FAV\% 20-\%202016\%20Annual\%20Monitoring\%20Report.pdf

CDWR (2013) California Water Plan Update 2013. Investing in innovation and infrastructure Volume 1: the strategic plan. Bulletin 160-13. Sacramento CA

Champion P, Tanner C (2000) Seasonality of macrophytes and interaction with flow in a New Zealand lowland stream. Hydrobiologia 441:1-12

Cordo H, Center TD (2000) Watch out water-hyacinth! New jungle enemies are coming. Agric Res 10-12. https:// agresearchmag.ars.usda.gov/AR/archive/2000/Mar/ water0300.pdf

Finlayson BJ (1983) Water hyacinth: threat to the Delta? Outdoor California 44:10-14

Garamendi J, Nielsen J (1982) Senate bill no. 1344, Chapter 2, Article 2, Section 64

Green RH (1979) Sampling design and statistical methods for environmental biologists. Wiley Interscience, Chichester

Greenfield BK, Siemering GS, Andrews JC, Rajan M, Andrews SP Jr, Spencer DF (2007) Mechanical shredding of water hyacinth (Eichhornia crassipes): effects on water quality in the Sacramento-San Joaquin River Delta California. Estuar Coast 30:627-640

Hestir EL, Brando VE, Bresciani M, Giardino C, Matta E, Villa P, Dekker AG (2015) Measuring freshwater aquatic ecosystems: the need for a hyperspectral global mapping satellite mission. Rem Sens Environ 167:181-195. https:// doi.org/10.1016/j.rse.2015.05.023

Jassby AD, Cloern JE (2000) Organic matter sources and rehabilitation of the Sacramento-San Joaquin Delta (California USA). Aquat Conserv: Mar Freshw Ecosyst 10:323-352

Khanna S, Santos MJ, Hestir EL, Ustin SL (2012) Plant community dynamics relative to the changing distribution of a highly invasive species Eichhornia crassipes: a remote sensing perspective. Biol Invasions 14:717-733

Khanna S, Bellvert J, Shapiro K, Ustin SL (2015) Invasions in state of the estuary 2015: status and trends updates on 33 indicators of ecosystem health. The San Francisco Estuary Partnership Oakland California, USA

Kuznetsova A, Brockhoff PB, Christensen RHB (2016) lmerTest: tests in linear mixed effects models version 2.033. $\mathrm{R}$ package. https://CRAN.R-project.org/package= lmerTest

Lenth RV (2016) Least-squares means: the R package lsmeans. J Stat Softw 69:1-33. https://doi.org/10.18637/jss.v069.i01 
Lynch JJ, King JE, Chamberlain TK, Smith AL (1947) Effects of aquatic weed infestations on the fish and wildlife of the Gulf States. US Dept Inter Spec Sci Rep 39:1-71

Mahardja BM, Young MJ, Schreier B, Sommer T (2017) Understanding imperfect detection in a San Francisco Estuary long-term larval and juvenile fish monitoring programme. Fish Manag Ecol 24:488-503. https://doi.org/ 10.1111/fme. 12257

Marine KR, Cech JJ (2004) Effects of high water temperature on growth, smoltification, and predator avoidance in juvenile Sacramento River chinook salmon. N Am J Fish Manag 24:198-210

Masifwa WF, Twongo T, Denny P (2001) The impact of water hyacinth Eichhornia crassipes (Mart) Solms of the abundance and diversity of aquatic macroinvertebrates along the shores of northern Lake Victoria Uganda. Hydrobiologia 452:79-88

Newcomb J, Pierce L (2010) Low dissolved oxygen levels in the Stockton deep water shipping channel: adverse effects on salmon and steelhead and potential beneficial effects of raising dissolved oxygen levels with the aeration facility. California Department of Water Resources, CA

Nobriga ML, Sommer TR, Feyrer F, Fleming K (2008) Longterm trends in summertime habitat suitability for Delta smelt, Hypomesus transpacificus. San Franc Estuary Watershed Sci. https://doi.org/10.15447/sfews. 2008v6iss1art1

Penfound WT, Earle TT (1948) The biology of water hyacinth. Ecol Monogr 18:447-472

Perna C, Burrows D (2005) Improved dissolved oxygen status following removal of exotic weed mats in important fish habitat lagoons of the tropical Burdekin River floodplain Australia. Mar Pollut Bull 51:138-148

Polansky L, Newman KB, Nobriga ML, Mitchell L (2018) Spatiotemporal models of an estuarine fish species to identify patterns and factors impacting their distribution and abundance. Estuar Coast 41:572-581. https://doi.org/ 10.1007/s12237-017-0277-3

R Core Team (2016) R: a language and environment for statistical computing. R Foundation for Statistical Computing Vienna Austria. https://www.R-project.org/. version 3.3.2 "Sincere Pumpkin Patch"

Rai DN, Munshi JD (1979) The influence of thick floating vegetation (Water hyacinth: Eichhornia crassipes) on the physico-chemical environment of a fresh water wetland. Hydrobiologia 62:65-69

Rommens W, Maes J, Dekeza N, Inghelbrecht P, Nhiwatiwa T, Holsters E, Ollevier F, Marshall B, Brendonck L (2003) The impact of water hyacinth (Eichhornia crassipes) in a eutrophic subtropical impoundment (Lake Chivero Zimbabwe). I. Water quality. Archiv für Hydrobiol 158:373-388

Ruhl CA, Schoellhamer DH (2004) Spatial and temporal variability of suspended-sediment concentration in a shallow estuarine environment. San Francisco Estuary and Watershed Sci. http://repositories.cdlib.org/jmie/sfews/vol2/ iss $2 /$ art 1

Stacey MT, Brennan ML, Burau JR, Monismith SG (2010) The tidally averaged momentum balance in a partially and periodically stratified estuary. J Phys Ocean 40:2418-2434

Swanson C, Reid T, Young PS, Cech JJ (2000) Comparative environmental tolerances of threatened delta smelt $(H y$ pomesus transpacificus) and introduced wakasagi $(H$. nipponensis) in an altered California estuary. Oecologia 123:384-390

Toft JD, Simenstad CA, Cordell JR, Grimaldo LF (2003) The effects of introduced water hyacinth on habitat structure invertebrate assemblages and fish diets. Estuaries 26:746-758

Villamagna AM, Murphy BR (2010) Ecological and scoioeconomic impacts of invasive water hyacinth (Eichhornia crassipes): a review. Freshw Biol 55:282-298

Vitousek PM (1990) Biological invasions and ecosystem processes: towards an integration of population biology and ecosystem studies. Oikos 57:7-13

Waltham NJ, Fixler S (2017) Aerial herbicide spray to control invasive water hyacinth (Eichhornia crassipes): water quality concerns fronting fish occupying a tropical floodplain wetland. Trop Conserv Sci 10:1-10. https://doi.org/ 10.1177/1940082917741592

Willoughby N, Watson IG, Lauer S, Grant IF (1993) An investigation into the effect of water hyacinth on the biodiversity and abundance of fish and invertebrates in Lake Victoria Uganda. NRI Project Report 10066 Ao32 g Natural Resources Institute Chathan, UK

Wolverton BC, McDonald RC (1979) Water hyacinth (Eichhornia-crassipes) productivity and harvesting studies. Econ Bot 33:1-10

Zimmels Y, Kirzhner F, Malkovskaja A (2006) Application of Eichhornia crassipes and Pistia stratiotes for treatment of urban sewage in Israel. J Environ Manag 81:420-428. https://doi.org/10.1016/j.jenvman.2005.11.014

Publisher's Note Springer Nature remains neutral with regard to jurisdictional claims in published maps and institutional affiliations. 